\title{
Gas Metal Arc Weld Cladding and its Anti-Corrosive Performance- A Brief Review
}

\author{
By Manas Kumar Saha* \\ Santanu Das ${ }^{\dagger}$
}

Cladding is a popular surfacing technique in which a thick material layer covers a relatively low cost structural material to enhance its mechanical properties as well as corrosion resistance properties to increase service life. Among different cladding techniques, an overview on cladding done by Gas Metal Arc Welding (GMAW) is included in this paper. Different special techniques used in GMAW for producing clad parts; their characteristics, microstructure and corrosion resistance properties are discussed. Influence of process parameters on microstructure and corrosion resistance of GMAW clad parts is broadly reviewed. Newer techniques being explored and used regarding GMAW cladding along with the future scope of work are also indicated in this paper. At the end, it can be stated that GMAW is one of the most effective processes for producing clad parts.

Keywords: Cladding, Corrosion resistance, GMAW, Process parameters, Welding.

\section{Introduction to Cladding by GMAW}

Cladding is a process where one material covers another either internally or externally. This type of process is used with metallic materials, optical fibres, construction materials, etc. Metal cladding is a type of exterior covering made of metallic material and its thickness is about 10 to $20 \%$ of total clad plate thickness (WiseGEEK, 2016). They are composites of two or more metals joined in a continuous manner by a metallic bond. Liner is another type of cover in which the joining type is intermittent (Nadkarni, 1988).

Clad metals are widely used in chemical, petroleum, nuclear, naval, aeronautical, service and maintenance industries.

Cladding may be produced by hot roll bonding, cold roll bonding, explosive bonding, centrifugal casting, brazing, and weld overlaying. It can also be produced by adhesive bonding, extrusion, and hot isostatic pressing (Davis, 1984). Different types of welding like explosive welding, resistance welding, electroslag welding, different types of arc welding like Shielded Metal Arc Welding (SMAW), Gas Tungsten Arc Welding (GTAW), Gas Metal Arc Welding (GMAW), Flux-Cored Arc Welding (FCAW), etc., different high energy intensity welding like laser beam welding (LBW), Plasma Arc Welding (PAW), etc. and some hybrid welding like LBW along with GMAW, etc. can successfully produce cladding. Among the processes employed for weld cladding, GMAW is widely accepted by the industry due to some distinct advantages (Lucas, 1994; Sreeraj and Kannan, 2012).

*Kalyani Government Engineering College \&Engineering Institute for Junior Executives, India. ${ }^{\dagger}$ Professor and Head, Kalyani Government Engineering College, India. 
GMAW cladding method was reported to have high reliability, all position capability, high production rate, suitability for applying to ferrous and non-ferrous materials, cleanliness and ease of mechanization. It is also easy to use, cheap and does not use flux (Saha et al., 2015).

Objective of this paper is to discuss the effectiveness of GMAW cladding among other cladding processes. Influence of different process parameters is discussed that can improve clad quality. Improving quality of cladding by optimum use of process parameters is also reviewed. Influence of favourable microstructure and weld bead in improving corrosion resistance of clad part is also discussed along with the outline of future scope of work.

\section{Influences of Different Parameters on GMAW Cladding}

One should consider favourable working parameters influencing weld bead produced by GMAW. Several experiments were conducted to evaluate the effect of process parameters of gas metal arc welding using $100 \% \mathrm{CO}_{2}$ gas shield (Sabiruddin et al., 2009; Sarkar, and Das, 2011; Sabiruddin et al., 2013; Saha et al., 2012). Elaborate experiments were conducted for GMAW using austenite stainless steel wire electrode (Khara et al., 2011; Verma et al., 2013a; Verma et al., 2013b). In both cases, welding current, welding voltage, torch travel speed, nozzle-to-tip distance, shielding gas composition, etc. took major role to determine the quality of weldment. Gas flow rate, nozzle angle with vertical, etc. played secondary role for determining quality of weld. The well accepted ranges of different process parameters for different materials combinations (metal substrate and clad layer) were investigated. For austenitic stainless steel (316) cladding on low alloy steel produced by GMAW using $\mathrm{CO}_{2}$ as shielding gas, minimum corrosion rate was found at $100 \mathrm{~A}$ current, $8.7 \mathrm{~mm} / \mathrm{s}$ torch travel speed and 24 volt (Khara et al., 2016). In case of another low alloy base material, the austenitic stainless steel cladding exhibited maximum corrosion resistance at $145 \mathrm{~A}, 26 \mathrm{~V}$ and $535.8 \mathrm{~mm} / \mathrm{min}$ travel speed (Verma et al., 2017). Figure 1shows variation of microstructures of austenitic stainless steel cladding on low alloy steel base materials exhibiting maximum corrosion resistance within experimental domain. However, there lies scope for exploring appropriate process parameters for different materials used in engineering field. 
Figure 1. Microstructure of 316 Austenitic Stainless Steel with Two Variations on Cladding on Low Alloy Steel (Khara et al., 2016)

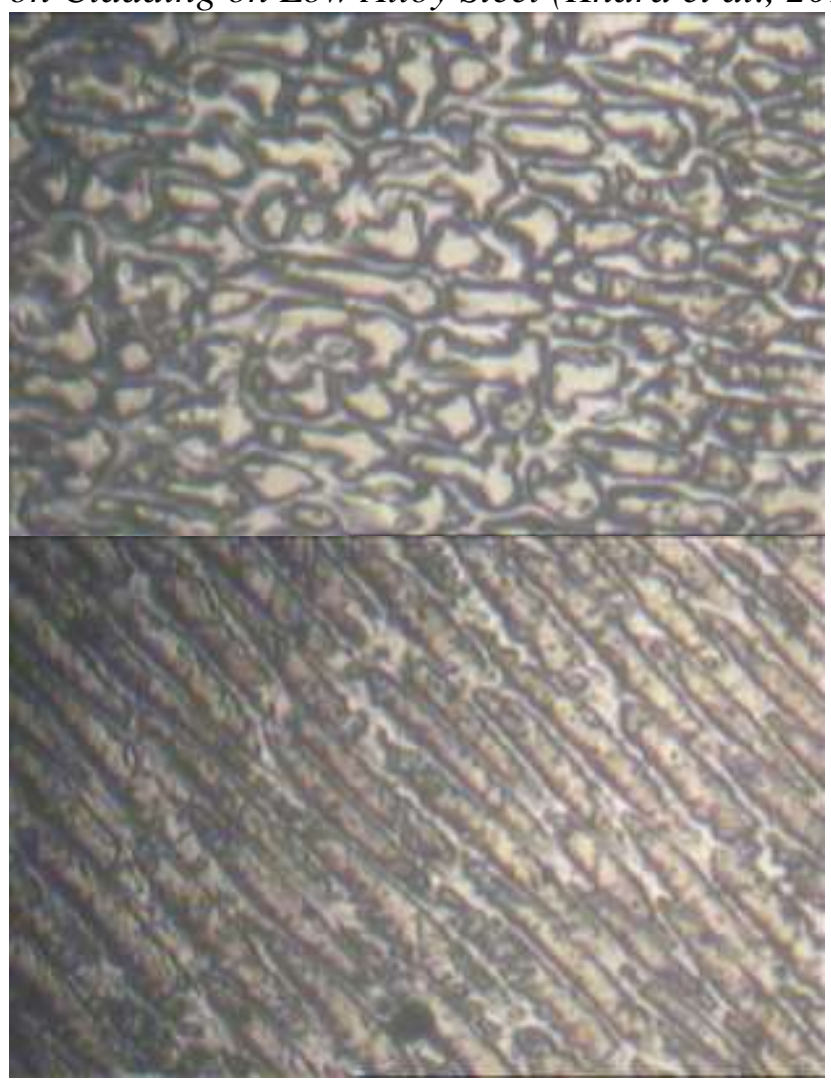

The mechanical strength of GMAW clad metal is influenced not only by the composition of the metal, but also by the clad bead shape. The clad bead shape is an indication of bead geometry. Unlike welding, the objective of cladding is quite different. In case of cladding, the penetration of weld bead should be minimum, so as to keep the dilution at minimum level. The acceptable clad bead geometry depends broadly on heat input which further depends on arc voltage, welding current, and arc travel speed. Weld bead geometry also depends on gas flow rate, wire feed rate, welding speed, torch angle, nozzle- tip distance, etc. Hence, the relationship between input process parameters and bead parameters are necessary to study the clad bead geometry and its shape relationships. This may be achieved by selecting proper design of experiment (Montgomery, 1984) and development of mathematical models. Several experiments were conducted to develop mathematical models among process parameters in case of GMAW cladding applied to various materials. There is no such general equation or relationship existing among all parameters for all materials. The relation varies with variation of alloying elements.

Going by the above, cladding of structural steel with duplex stainless steel filler wire with flux core using GMAW process was performed to achieve optimum process parameters through Response Surface Methodology (RSM) technique to produce cladding that would have desired properties (Shahi and Pandey, 2011). Process parameters were also optimized to get better weld bead 
geometry using Taguchi method and regression analysis technique in another work (Kolahan and Heidari, 2009). Datta et al. (2008) and (2009) applied grey based Taguchi method and PCA-based hybrid Taguchi method in some experiments using submerged arc welding to optimize process parameters and obtained better weld bead geometry. An experimental study was carried out to develop mathematical models for predicting clad bead geometry and its shape relationships of austenitic stainless steel claddings deposited by gas metal arc welding process (Kannan and Yoganandh, 2010). In one such experiment of GMAW cladding, optimization of process parameters was done by Artificial Neural Network (ANN) and multiple regression method (Saha and Das, 2016). The optimum process parameters were tried to determine based on central composite rotatable design with full replication technique in a recent study to evaluate minimum dilution by ANOVA or RSM (Sreeraj et al., 2013a; Sreeraj et al., 2013b). In a recent study, Minitab 15 was used as a mathematical tool for optimizing process parameters to get a corrosion resistant single layer cladding on mild steel by GMAW method (Kumar et al., 2012).

In a more recent work, it has been observed that within a certain range of values of process parameters in case of duplex stainless steel cladding on low alloy steel by GMAW process, weld bead parameters like height, width, depth of penetration, penetration shape factor (PSF) and reinforcement form factor (RFF) keep linear relationship with heat input on the whole. Linear relations among them were obtained by regression analysis and the results agree with the real data with negligible error (Mondal et al., 2016). It was observed that height, width, reinforcement, PSF and RFF increase with increase in heat input. Among all weld bead parameters, weld width was found to increase in faster mode with increase in heat input.

The metal transfer mode is one of the determining factors for weld bead geometry as well as the microstructure. Some welding defects are also caused due to some metal transfer mode which is also dependent on welding current, arc voltage, tip-to-nozzle distance, gas flow rate, heat input, etc. In GMAW-P, process the drop detachment mechanism was investigated in case of steel and aluminium and the result indicated different forces responsible for this (Waszink and Piena, 1986). In another study, it was observed that the pulsing parameters greatly influenced the characteristics of the clad layer and interactive layer. GMAW-P produced lower dilution, finer microstructure of the clad layer relative to the clad part produced by constant current GMAW. It was concluded because of the capability of the pulsed current GMAW to produce a comparatively finer microstructure, higher deposition, lower dilution and smaller depth of fusion of the cladding and lower hardness of an interactive layer formed in the cladding adjacent to the base metal (Ghosh et al., 1998).

In an experimental investigation, drop detachment and drop velocity of molten metal were explored during GMAW-P in thin aluminium sheet. The result showed that transfer of droplet significantly controlled quality of weld. The role of frequency and duty cycle were preliminarily found to control drop transfer. Pulsing variables, namely peak current, base current, peak time and base time were reported to have influenced metal transfer mode in GMAW-P 
technique (Praveen et al., 2006). Optimization of process parameters to achieve controlled weld bead penetration in Pulsed Gas Metal Arc Welding was tried in another work using Genetic Algorithm. Process parameters selected were pulse frequency, wire feed rate, thickness of the plate, wire feed rate/travel speed ratio, and peak current (Kanti et al., 2013).

Convexity Index, a ratio of weld bead height to weld bead penetration, is an important factor for weld bead geometry. It was observed that in Pulsed MIG (P-MIG) welding, convexity index could be controlled by process parameters like welding current, travel speed and nozzle-tip distance. RSM (response surface methodology) was used as the mathematical model to DOE (Prabhu et al., 2014). One similar experimental work was conducted in pulsed GMAW cladding of $316 \mathrm{~L}$ stainless steel on $65 \mathrm{X}$ pipeline steel to evaluate influence of process parameters on weld bead geometry. It was observed that width, height, depth and dilution of weld metal increased with increasing wire feed rate, but the contact angle decreased first and again increased after reaching a minimum value. Also, the values of width, depth, height, and the contact angle of weld metal declined with rising values of both welding speed and dilution. Dilution enhanced on an average of about $6 \%$ and angle of contact reduced to about $7^{0}$ with decreasing electrode extension. Mathematical models were generated to evaluate relationship among process parameters with dilution and weld bead geometry (Nouri et al., 2005).

Automated robotic gas metal arc welding (GMAW) was applied to develop controlled-dilution, high-quality stainless-steel GMAW cladding procedures that met stringent porosity requirements. To do so, commercially available $308 \mathrm{~L}$ and 309L filler metals were used to minimize contact tip wear and to maximize arc-on time between tip changes. Constant voltage GMAW (CV GMAW) and pulsed GMAW were evaluated using two shielding gas mixtures. Mathematical model was created to investigate the effect of welding mode, welding technique, electrode chemistry, and the shielding gas used on porosity of the clad layer (Purslow, 2013).

Since long, type 312 stainless steel containing $\mathrm{Cr}$ ( $28 \%$ to $32 \%$ by wt.) in the weld wire had increasingly been used a preferred overlay alloy for aggressive batch digesters. However, because of its high chromium content, type 312 SS weld overlay was reported to be susceptible to weld solidification cracking when applied to carbon steel substrate. Pulsed spray GMA welding in vertical mode produced crack free overlay successfully (Lai and Hulsizer, 1999).

A number of experiments were conducted for exploring better cladding material, newer welding technique or modification of techniques, better mathematical model to relate the influence of process parameters, checking the response parameter, making different standards, etc. However, most of the experiments were conducted to control the process parameters of GMAW to get the best possible weld bead geometry. In case of cladding, the prime challenge for engineers is to keep minimum dilution of filler metal to restrict the fall of performance of filler materials as well as to make sufficient strength of the joint of two dissimilar metals. 
In an early experiment, $12 \%$ dilution had been achieved in austenitic stainless steel cladding on structural steel by controlling process parameters in automated GMAW process (Murugan and Parmar, 1997). In one recent experiment, influence of process parameters on dilution was investigated in case of GMAW cladding of austenitic stainless steel on structural steel substrate. Process parameters were chosen as welding current, welding speed, gun angle, contact tip-to-work distance and pinch. Full factorial design was constructed and mathematical model used was artificial neural network and particle swarm optimization tool. The proposed model gave results which were very near to the real data (Sreeraj et al., 2013c). In another austenitic stainless steel cladding experiment by GMAW, process parameters were selected as welding voltage, welding current, welding speed, bead offset, etc.

Heat input to the cladding process tends to control bead geometry, composition, microstructure, and ferrite content and corrosion properties. Bead geometry influences the number of welding passes required to deposit on the given surface. The percentage of offset influences the dilution of filler metal and thickness of the deposited layer. By means of simulation, it was observed that wire feed rate and welding speed influenced weld bead geometry significantly (Senthikumar et al., 2014). In another investigation, the influence of heat input on super duplex stainless steel was found out. Process parameters like welding current, torch travel speed, tip-to-nozzle distance, welding gun angle were reported to have influence on weld bead geometry components along with different shape factors like reinforcement form factor (RFF) and penetration shape factor (PSF). Additionally RFF was reportedly influenced by melting rate and resistant heating of electrode, and PSF was affected by arc force and arc length (Senthikumar et al., 2015).

Trial runs with a combination of parameters were done to predict effects of welding variables on duplex stainless steel (E2209T0-1) cladding made on low carbon steel substrate. At a moderate heat input $(0.38 \mathrm{~kJ} / \mathrm{mm})$ corresponding to $28 \mathrm{~V}$ weld voltage, $145 \mathrm{~A}$ weld current and $516 \mathrm{~mm} / \mathrm{min}$ weld torch speed, favourable microstructure of the clad portion was obtained. At this condition, corrosion rate was shown to be minimum (Verma et al., 2014).

Comparison of the effect of gas metal arc welding techniques on some mechanical properties of duplex stainless steel was made in another experimental study. The post weld heat treatment of welded samples was carried out (quenching in engine and neem oil) and the result indicated that the post heat treatment process influenced the mechanical property of clad part made by GMAW a lot. The research also showed that the stress relief heat treatment gave better strength up to $\left(331 \mathrm{MN} / \mathrm{m}^{2}\right)$ than that were quenched in lubricating oil (329 $\left.\mathrm{MN} / \mathrm{m}^{2}\right)$ and neem oil $\left(222 \mathrm{MN} / \mathrm{m}^{2}\right)$, but the reverse trend was noticed in terms of toughness (Ibrahim et al., 2013).

Investigation was done to check the effect of auxiliary preheating of the solid filler wire in mechanized gas metal arc welding (GMAW) process (by preheating the filler wire autonomously prior to its coming out from the torch by the help of a specially designed torch) on the quality of the single layer stainless steel overlay. External preheating of the filler wire developed greater contribution of 
arc energy by resistive heating due to which significant drop in the main welding current values were observed. Resulting weld bead was of low dilution. It was found that claddings obtained during the preheating arrangement possessed higher content of ferrite phase along with higher amount of alloying elements like chromium, nickel and molybdenum and lower content of carbon compared to conventional GMAW claddings. The resulting microstructure provided overlays with superior mechanical and corrosion resistance properties. The proposed process was reported to be technically superior and had increased productivity with low cost (Shahi and Pandey, 2008). Another approach was adopted to get optimum weld bead geometry in case of pre heated filler-GMAW process for stainless steel cladding using Response Surface Methodology (Sreeraj et al., 2013c).

A novel welding method named consumable double electrode with a single arc (DESA)-GMAW was proposed providing controlled heat input with increased filler wire deposition rate. The welding process could be quite stable with appropriate welding parameters: one filler wire kept arcing stably with regular metal transfer process, and the other filler wire was short-circuited with workpiece all through and was fed into the welding pool stably and smoothly. The transverse section of the weld bead was analyzed, and it was found that the penetration could be effectively decreased with high metal deposition rate by using consumable DESA-GMAW (Shahi, and Pandey, 2011; Wei et al., 2013).

Cladding by GMAW is basically welding between two dissimilar metallic materials and the joint is prone to crack propagation due to dissimilar thermal co-efficient of expansion of them. Several techniques were adopted to prevent crack formation at the interface region. One such process in case of GMAW welding is torch weaving technique. One experimental investigation was conducted to evaluate influence of torch weaving with duplex stainless steel and structural steel combination by means of automated synergic GMAW process. Flatness of the weld deposited layer was determined by weaving techniques. It was concluded that weaving decreased dilution rate and increased the Ferrite Number. However, no obvious effect on microstructure, porosity and hardness as a result of using weaving was observed (Tasalloti et al., 2014).

Other important parameters, which may determine clad bead geometry, are the eccentricity and arc rotational speed. One developmental work on automated robotized welding process was carried on in which automatic high speed rotating arc welding could be performed. In that process, the wire was mechanically rotated. Multiple wires could be engaged for welding thick plates. The weld bead formed was flat, wide, and less penetrative compared with ordinary GMAW bead (Munez et al., 2010).

In another experiment, the arc rotation mechanism and the effect of arc rotational speed at constant eccentricity on weld bead geometry were investigated (Kang and $\mathrm{Na}$, 2003). One experiment was conducted to determine the effects of eccentricity and arc rotational speed on 5083 aluminum alloy weld bead geometry in pulsed GMAW. It was observed from the investigation that eccentricity had the maximum effect on convexity followed by arc rotational speed, ratio of 
wire feed rate to travel speed and wire feed rate whereas wire feed rate had relative maximum effect on penetration (Rao, 2004).

Recently, narrow groove welding is reported to be an important technique for increasing productivity in the manufacture of thick walled components. The nature of the process demands an automated approach and precise control to ensure consistently good weld quality. The prime objective of narrow groove welding is to maintain uniform and sufficient penetration at both groove faces. One investigation (Sugitiani et al., 1991) studied the arc shape and bead characteristics in narrow groove gas metal arc welding by the use electromagnetic arc oscillation. Based on the result obtained, appropriate welding and oscillation conditions were selected to satisfy high weld quality.

The arc rotation mechanism system can be used to develop the flat and broad weld bead by means of the centrifugal force of the rotating arc at welding. In one investigation, four input process parameters were selected in a welding which used an arc rotation mechanism. A number of experiments was conducted on $5083 \mathrm{H} 111$ aluminum alloy square butt joint plates using full factorial design of experiments. It was observed from the investigation that eccentricity had maximum effect on convexity. Convexity also depended on arc rotational speed, ratio of wire feed rate to travel speed and wire feed rate. It was also observed that the wire feed rate had relatively maximum effect on penetration (Kumar et al., 2011).

\section{Cladding Microstructure}

The microstructure of clad layer and heat affected zone (HAZ) greatly influence corrosion resistance property as well as mechanical property. Different alloying elements present in clad layer create variation in microstructure that is responsible for various properties.

Cladding microstructure is greatly influenced by dilution of the cladding material with the base material. Dilution is the reduction in alloy content of a weld deposit by the mixing of the deposited metal with a part of the base metal which is melted during welding. Dilution varies with welding parameters like arc current, travel speed, electrode diameter and so on. Dilution is commonly expressed as the percentage of base metal that has been mixed with the weld metal. Figure 2 represents clad layer (A) on base metal and penetrated layer which is the mixture of the two layers (B). Dilution is calculated as follows:

$$
\text { Dilution }=\frac{B}{A+B} \times 100(\%)
$$


Figure 2. Cladding Layer on Base Metal

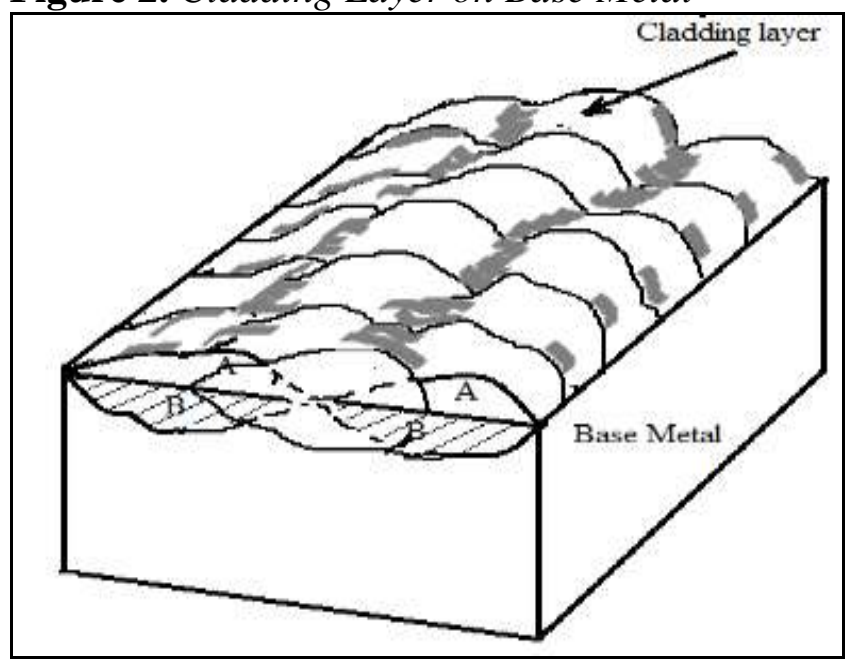

Dilution has a major influence on the structure of deposited weld metal and fusion boundary. Amount of dilution and depth of penetration primarily depend upon welding conditions. Moreover, dilution will be affected by welding technique and sequence.

A weld deposit of stainless steel laid on the surface of low alloy steel for improved corrosion resistance is an example of a weld overlay. One work aimed at studying structure-property correlations in weld overlay clad high strength low alloy steel with austenitic stainless steel of AISI 347 grade. The base plate microstructure near the interface comprised of ferrite and bainite. The microstructure developed away from the interface comprised of tempered bainite/ martensite structure. Grain coarsening and decarburization were observed near the interface. Stainless steel exhibited austenite phase having dendritic structure. Tensile strength, notch-tensile strength and Charpy impact energy of the base plate were found to be higher than that of the interface. Maximum value of microhardness was observed on the clad layer near interface. Shear bond strength of the weld overlay-interface was higher than shear strength of the base plate. Electron probe microanalysis across the bond interface indicated linear change in concentration of $\mathrm{Cr}, \mathrm{Ni}, \mathrm{Mn}, \mathrm{Cu}, \mathrm{Mo}, \mathrm{Nb}$ and $\mathrm{Si}$ between the level appropriate to the clad layer and base metal (Kumar et al., 2011). It was observed that Fe$\mathrm{Ni}-\mathrm{Cr}$ (basic stainless steel) microstructure depended on solidification process and cooling rate. 12 microstructures were seen for 300 series of austenitic steel formed at different cooling rate (Rao et al., 2011).

Other than primary phases of austenite, ferrite, etc., there are various phases which are responsible for mechanical properties as well as corrosion resistance properties. One work done focused on the effect of secondary austenite $\left(\gamma_{2}\right)$ on corrosion resistance of welded joints. The welded joints were produced by pulsed gas metal arc welding (GMAW-P) with three different heat input. Each joint and their respective sub-regions were distinguished minutely and the results were correlated with double loop electrochemical potentio-dynamic reactivation (DL-EPR) and sulphide stress corrosion tests. The results suggested a good agreement between the DL-EPR and the four point bending tests. It was 
also verified that the ordinary presence of $\gamma_{2}$ did not necessarily reduce corrosion resistance properties (Elmer et al., 1989). Figure 3(a, b) show microstructure of duplex stainless steel cladding and austenite stainless steel cladding respectively as observed by the authors (Saha and Das, 2016) of this article.

To avoid problem like sensitization and stress corrosion cracking austenite phase needs be modified further. Newer materials like Duplex stainless steels were thus introduced. It had dual phases-austenite and ferrite phases. Lower carbon content and controlled nitrogen content increase resistance to pitting corrosion of duplex stainless steel. 40\%-50\% ferrite present in duplex stainless steel reduces the chance of stress corrosion cracking (ASM International, 2006, 2006). Duplex weld metals, however, were not been studied in such detail as the duplex stainless steel. For this, the properties of duplex weld metals are less known. The proportion of austenite and ferrite phases is approximately equal in annealed wrought duplex stainless steel. The property of duplex stainless steel, on the whole, is governed by the presence of micro duplex structure. Fusion welding process, however, gives quite different microstructure in fusion and heat affected zone (HAZ) from that of the base metal. This causes change in weld property. It was observed, in an investigation, that the $\%$ phase of the weld (i.e. austenite and ferrite $\%$ in the clad part) could be determined by the parent metal, filler material, rate of heating, cooling rate, maximum temperature, etc. The grade of duplex or super duplex stainless steel is judged by the PREN $(\mathrm{PREN}=\mathrm{Cr} \%+3.3 \% \mathrm{Mo}+16 \% \mathrm{~N})$ value which may also be responsible for assessing corrosion resistance property (Dreilich et al., 2014).

Figure 3. a) Duplex SS, 200X, Etchant: Ralf's Reagent + Waterless Kalling'

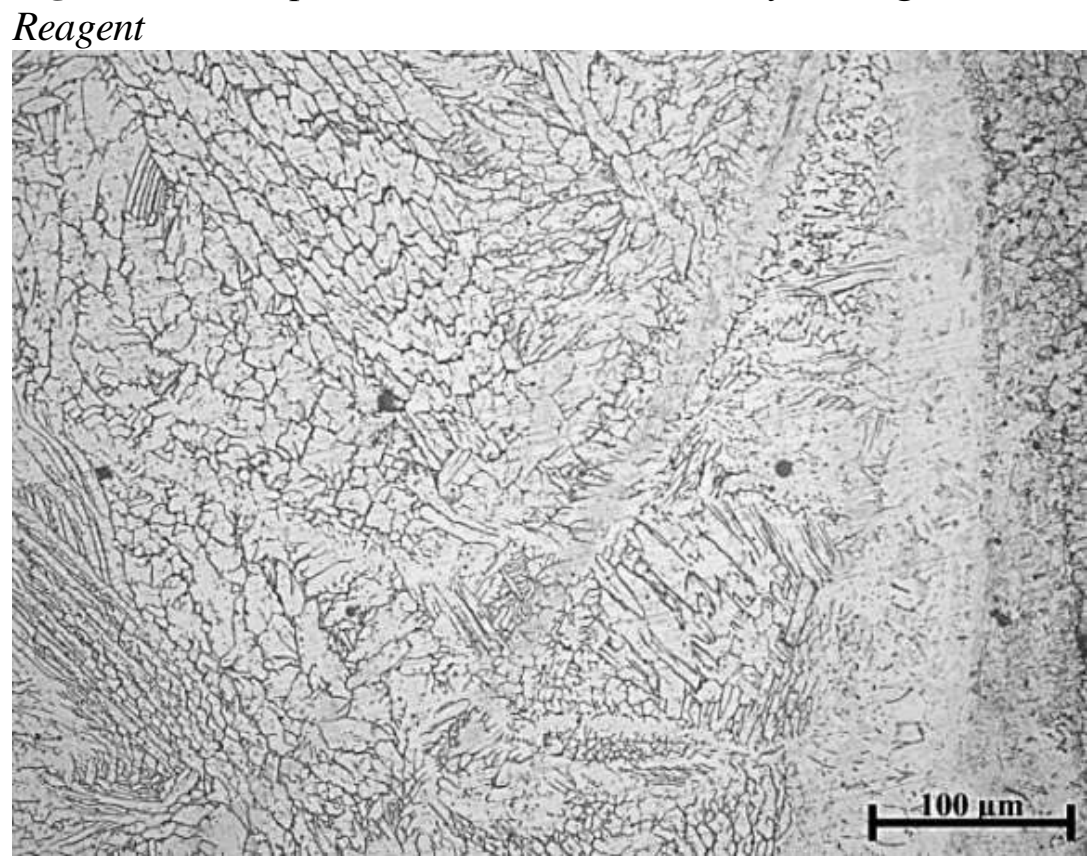


Figure 3. b) Austenite SS Cladding, 200X, Etchant: Ralf's Reagent

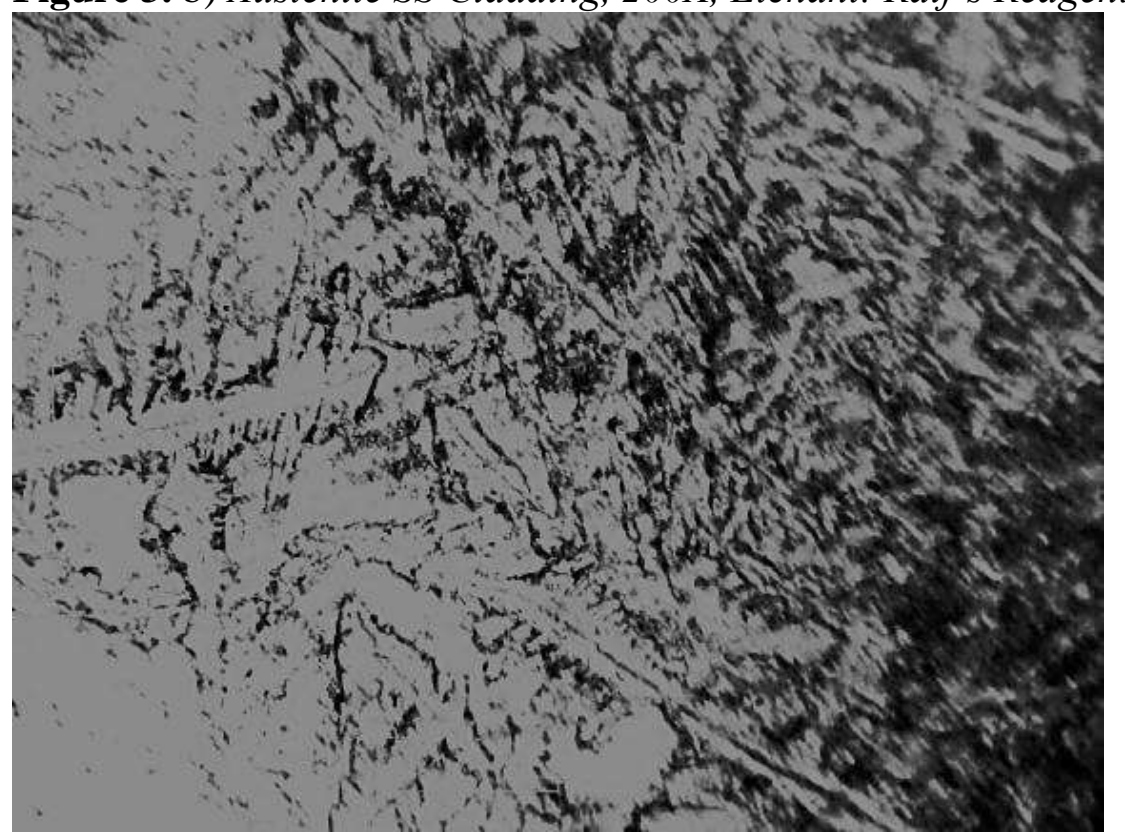

Cladding of stainless steel is greatly influenced by ferrite number when there are austenite-ferrite combination (duplex) phases present in stainless steel. Several methods are explored to determine ferrite number. $\mathrm{Cr}$ and $\mathrm{Mo}$ increase the ferrite content whereas Ni and N stabilize the austenite (Karlsson, 2000).

Duplex stainless steels contain alloying elements like $\mathrm{Cr}$, Mo, and $\mathrm{N}$ which exhibit good corrosion/erosion resistance properties in acidic, caustic as well as marine environment. But depending on fabrication process, welding technique and improper heat treatment, intermetallic secondary phases like chi and sigma phases may be developed which tend to decrease $\mathrm{Cr}$ or $\mathrm{Cr} / \mathrm{Mo}$ ratio in the matrix leading to inter-granular corrosion, pitting corrosion and stress corrosion cracking. Care should be taken so that no or less secondary phases should be formed and balance of austenite and ferrite phases should be maintained to get maximum corrosion resistance (Chan and Tjong, 2014).

\section{Corrosion Resistance Property of Cladding}

Most of the engineering components demand both high strength and corrosion resistant materials to use to guarantee long service life. Corrosion resistance is a property of a material by virtue of which it can resist loss of weight, strength, performance, and aesthetics against external or environmental causes. Often the strength can best be achieved by the use of steels which do not possess the required corrosion resistance property. A possible solution is to provide the combination of attributes of high strength and corrosion resistance to structural components by cladding the surface of the steel with a metallurgic ally compatible corrosion resistant alloy. Standard corrosion test methods were also developed to evaluate corrosion resistance property against different types of corrosion by 
cladding materials (ASM International, 2006). Selection of proper standard corrosion test for different welding processes affects the actual performance of the process (Holmberg and Bergquist, 2008).

Several experiments were performed to evaluate the influence of alloying elements in the microstructure and their properties of stainless steel. One constitutional diagram had been generated on the basis of microstructure and the effect of particular alloying element on it. Empirical relation was developed to predict the correct microstructure depending upon presence of alloying elements within the proposed diagram value domain (Balmforth and Lippold, 2000).

Several attempts were made to determine different effects of welding process, cladding material, dilution, microstructure, phase structure, chemical composition of the corrosive environment, and other various parameters on corrosive property of the clad overlay. High temperature corrosion is one of the key features and several investigations were made to understand the effect of different parameters on it so that engineering materials can survive in such corrosive environment.

Other than pitting corrosion, cavitation erosion plays a vital role in corrosion. In one experiment, the cavitation erosion and corrosion characteristics of various engineering alloys including grey cast iron, steels, copper-based alloys and stainless steels were studied by means of a $20 \mathrm{kHz}$ ultrasonic vibrator in a solution of distilled water and $3.5 \% \mathrm{NaCl}$ at $23^{\circ} \mathrm{C}$. The contributions of pure mechanical erosion, electrochemical corrosion, and the relative effect of erosion and corrosion to the overall cavitation erosion-corrosion in $3.5 \% \mathrm{NaCl}$ solution were determined. It was found that in this particular environment, the effect of corrosion on the overall cavitation erosion-corrosion was severe in mild steel and grey cast iron, and negligible in stainless steels. Stainless steels only suffered pure mechanical erosion in $3.5 \% \mathrm{NaCl}$ solution in the presence of cavitation owing to the adverse local environment for pit growth (Kwak et al., 2000).

For overlay alloy 625 used in boiler tube, the corrosion resistance against simulated molten salt medium was investigated in one work. Main mechanisms for the corrosion were internal oxidation, sulfidation and pitting corrosion. The presence of a significant amount of Fe made the dendritic structure of the weld prone to preferential corrosion. Preferentially corroded (Mo, Nb)-depleted dendrite cores acted as potential sites for crack initiation from the surface layer. Penetration of molten phase into cracks caused acceleration to crack propagation mainly through the dendrite cores following crack branching or widening (Zahrani and Alfantazi, 2013). Further observation from the same type of experiments reveals that $\mathrm{Cr}$ and $\mathrm{Fe}$ alloying elements are detrimental for hot corrosion cracking (Zahrani and Alfantazi, 2014).

Different cladding materials are used to enhance corrosion resistance properties of the substrates. Among them, duplex stainless steel and super duplex steel electrodes are becoming the focus of attention recently. Duplex stainless steel contains ferrite and austenite phases simultaneously. These categories of steels contain mainly the alloying elements like $\mathrm{Cr}, \mathrm{Ni}, \mathrm{Mo}$, and N. Some duplex steels also contain $\mathrm{Mn}, \mathrm{Cu}$ and $\mathrm{W}$. Austenite shows ductility at lower temperature and ferrite increases resistance to corrosion cracking. Duplex stainless steel 
exhibited a combination of corrosion resistance properties including stress corrosion cracking (SCC) resistance, pitting and crevice corrosion resistance, etc. along with better mechanical properties high strength and toughness than commonly utilized austenitic and ferritic stainless steels.

In one recent work, pure copper cladding on a pressure vessel A516 Gr. 70 steel plate by means of both friction stir welding and GMAW (Shen et al., 2015).

It was observed that in case of duplex stainless steel cladding on low alloy steel substrate, concentration of nitrogen in weld deposits affected significantly on microstructure, low temperature toughness and resistance to pitting corrosion. The nitrogen concentration in weld deposit was observed to be influenced by both heat input and shielding gas composition (Chakrabarti et al., 2013).

Investigations showed that cladding layer made by duplex stainless steel 2209 alloy having nominal composition of $22 \% \mathrm{Cr}, 9 \% \mathrm{Ni}$ and $3 \% \mathrm{Mo}$ became more passive (corrosion resistant) on modifying cathodically with about $0.3 \%$ $\mathrm{Ru}$ (Ruthenium). The weight-loss data showed that the dissolution of duplex stainless steel increased with increase in time. The weight-loss effect decreased remarkably in the presence of $\mathrm{Ru}$ in the alloy. Electrochemical tests showed $\mathrm{Ru}$ to shift the corrosion potential in the positive direction thereby decreasing corrosion current density. As a result, both uniform and pitting corrosion decreased, and polarization resistance of the duplex stainless steel increased. Results showed clearly the presence of Ru in DSS alloy 2209 increasing its passivity against corrosion in acidic as well as neutral chloride solutions (Serif, 2012). Earlier Serif (2011) found the corrosion behavior of duplex stainless steel alloy cathodically modified with minor ruthenium in concentrated sulfuric acid solutions and improve its corrosion resistance property.

Effect of welding variables on cooling rate and pitting corrosion resistance in Super Duplex Stainless weldment was studied in an experiment. This work was carried out to investigate the effect of welding variables, that included wire feeding rate, wire feeding technique, and heat input, on the cooling rate in both the weld and heat affected zone (HAZ) areas of multi-pass weldment in a super duplex stainless steel. Heat input was found to be an important variable to play a key role in governing the cooling time, and it could be further enhanced with increased preheat temperature. Cooling rate was not significantly affected by wire feeding rate, but it played a key role on the phase balance in the HAZ and weld. It also significantly affected the formation of intermetallic phases and corrosion resistance. Quite high corrosion resistance was obtained when a suitable cooling rate (using an intermediate heat input of $1.4 \mathrm{~kJ} / \mathrm{mm}$ ) with the conventional wire feeding technique was used (Serif, 2012).

In one experimental work, effects of bromide and chloride ion concentration and temperature on the pitting corrosion behaviour of commercial grade SAF2205 duplex stainless steel were explored. Pitting potential was found to decrease with an increase in temperature and bromide ion concentration. In the presence of chloride ions, pitting corrosion was not observed at room temperature. Critical pitting temperature in chloride-containing solution was estimated to be above $35^{\circ} \mathrm{C}$. It was also observed that pit initiation took place in austenite phase regions (Wang, 2005). 
In one experiment different fillers, duplex ER 2209 and two austenitic fillers (ER 316LSi and ER 308LSi), were used in this work. Dissimilar duplex austenitic welds showed a sharp reduction of the resistance to localized corrosion, the effect being less noticeable for the ER 316LSi electrode due to the presence of higher molybdenum content. On the other hand, the joint with ER 308 electrode produced the joint that had more uniform mechanical properties, having higher chrome content than ER 316LSi electrode (Adeli et al., 2010).

Application of clad components in modern industries like power plant, oil refinery, naval equipment, paper industries, chemical plant, etc. requires fining out appropriate cladding materials along with the technique that can yield high productivity. In a work, status of the modern overlay technology for applying a corrosion-resistant alloy on to the existing equipment for corrosion control was discussed briefly (Kumar et al., 2011). Corrosion problems and the successful overlay alloys used to solve them in boilers and in vessels in pulp mills and refineries were also described. Overlay of 'nickel-base alloy 625 ' was found to be extremely successful to minimize the chloride corrosion attack on water-walls and super heaters in waste-to-energy boilers. Both types of 309 SS and alloy 625 overlays were reportedly successful in reducing or even eliminating sulfidation attack on the water-walls of coal-fired boilers equipped with low NOx burners. Success was also reported in mitigating corrosion problems in kraft recovery boilers with the use of alloy 625 for floor tube and membrane overlays, and 309 SS and 625 overlays for corrosion protection in lower furnace water walls. Kraft digester was reportedly relied on 309 SS and 312 SS weld overlays for corrosion protection. Many vessels, towers and columns were reported to be weld-overlaid with austenitic alloys, such as, 309L, 317L, alloy 82, etc., in petroleum refineries.

For boiler tubes in power plant CNC programmed robot was introduced to produce quality cladding by 309L filler electrode in any position using pulsed GMAW which had yielded satisfactory result regarding corrosion resistance (Dutra et al., 2014).

Nickel chromium molybdenum alloys have excellent creep properties along with high corrosion resistance which finds a suitable application in Oil and Petro chemical industries. Cladding Ni alloys on carbon steel became a cheaper alternative that can provide a good corrosion resistance property which was produced by roll bonding, explosive welding, etc. It is simple and easy-to-work but enough care should be taken to control the weld chemistry so that Fe content should be restricted upto 5\%. Same principal was adopted successfully for GMAW cladding using Inconel 625 electrode wire (Elango and Balaguru, 2015).

\section{General Discussion on Cladding}

Quality of a weld joint depends on the weld bead shape and bead geometry such as bead width, height and penetration. Good quality weld bead requires larger weld bead width, height and penetration. Unlike welding, cladding requires low penetration so that dilution should be less. Ordinary GMAW yields deeper, wider and large deposited weld bead at higher heat input. The finger type 
penetration is predominant in pulsed GMAW which affects the quality of the welding. In arc rotation mechanism system, flat and broad weld bead can be achieved because of the centrifugal force of the rotating arc and penetration profile also can be improved. In every case penetration are to be minimized to reduce dilution.

The cladding quality can be improved by using optimum process parameters and so also heat input. The factors influences weld bead geometry mostly are welding current, welding speed, welding voltage, tip-to-nozzle distance, etc. Other process parameters like gas flow rate, welding gun angle, arc force, etc. influence bead geometry in weak way. Proper selection of process parameter improves corrosion/erosion resistance and mechanical strength. The selection of proper statistical tool is very useful for analyzing the relations among process parameters and bead geometry.

The performance of GMAW cladding can be improved by modification of processes using different pulse modes, active mode, dual torch method, weaving techniques, etc. The quality of clad part may also be improved by pre or post heat treatment, lowering heat input and controlling different process parameters.

Newer technique like DESA-GMAW improves deposition rate with decreased penetration. Autonomous pre-heating of electrode also lower welding current that also decrease heat input.

Different alloy steels had been used for cladding purpose. Duplex stainless steel, hyper/super duplex steels, etc. are become very popular choice for cladding.

Introducing rear earth elements in to the cladding layer as alloying elements can increase corrosion resistance or passivity in a severe corrosive environment. Balance of ferrite phase and austenite phase in the microstructure improves corrosion resistance in a great way. On the other hand, formation of secondary precipitation, intermetallic compound formation in the microstructure creates detrimental effect in corrosion resistance.

It can be stated that GMAW can be used as a cladding process that gives satisfactory corrosion resistance performance. Improved welding technique and choice of suitable process parameters can yield preferable welding geometry for cladding that should have low penetration, wide and low reinforcement weld bead. Good weld bead geometry and favourable microstructure with prominent ferrite phase enhance corrosion resistance property, and investigation may be further conducted to determine appropriate process conduction to achieve desirable corrosion-resistance. Post heat treatment, pre heat treatment may further improve the cladding microstructure. Different newer techniques those can deposit more cladding materials with less penetration or with application of low heat input should be introduced in future. Relationship between corrosion rates with different process parameters should be obtained for different set of base material- cladding material combination. Though cladding has lower penetration, care should be taken so that the cladding layer must have sufficient shear strength to prevent detachment it from the base metal. 


\section{Conclusions}

From the discussion made, it can be inferred that:

Gas Metal Arc Welding can well be utilized for cladding to obtain good corrosion resistance performance.

Selection of appropriate process parameters can yield desired weld bead geometry for cladding, that is, low penetration, low reinforcement and wide weld bead.

$>$ Favourable microstructure with prominent ferrite phase enhances corrosion resistance.

$>$ Post heat treatment and preheating may also improve cladding microstructure.

Newer techniques those can deposit more cladding materials with less penetration with application of low heat input are needed to be introduced in future.

$>$ Relationship between corrosion rates with different process parameters may further be explored for different set of base material-cladding material combination.

\section{References}

Adeli, M., Golozar, M. A. and Raeissi, K. 2010.Pitting corrosion of SAF2205 duplex stainless steel in acetic acid containing bromide and chloride.Chemical Engineering Communications, 197, p. 1404-1416.doi: http://bit.ly/2E3WdyK.

ASM International, 2006, Chapter.Basic understanding of weld corrosion.Corrosion of Weldments (\#05182G).http://bit.ly/2BZa43k.

Balmforth, M. C. and Lippold, J. C. 2000.A new ferritic-martensitic stainless steel constitution diagram, Welding Journal, 79, 12, p 339-345.

Chakrabarti, B., Das, S., Das, H. and Pal, T. K. 2013.Effect of process parameters on clad quality of Duplex Stainless steel using GMAW process.Transactions of the Indian Institute of Metals, 66, 3, p. 221-230.doi:10.1007/s12666-013-0246-x.

Chan, K. W. and Tjong, S. C. 2014. Effect of phase precipitation on the corrosion behavior of duplex stainless steels, Materials, 7, p. 5268-5304. Doi.10.3390/ma70 75268.

Datta, S., Bandyopadhyay, A. and Pal, P. K.2008.Grey-based Taguchi method for optimization of bead geometry in submerged arc bead-on-plate welding. The International Journal of Advanced Manufacturing Technology, 39, 11, p. 11361143. doi:10.1007/s00170-007-1283-6.

Datta, S., Nandi, G., Bandyopadhyay, A. and Pal, P. 2009. Application of PCA-based hybrid Taguchi method for correlated multicriteria optimization of submerged arc weld: a case study. The International Journal of Advanced Manufacturing Technology, 45, 276, p. 276-286.doi:10.1007/s00170-009-1976-0.

Davis, J.R. and Associates.1984. Stainless Steel Cladding and Overlays, ASM Specialty Handbook: Stainless Steels, 06398G, 1984,http://bit.ly/2EogSwI.

Dreilich, T., V., Assis, K. S. de., Sousa, F. V.V. de. And Mattos, O. R. 2014. Influence of multipass pulsed gas metal arc welding on corrosion behaviour of a duplex 
stainless steel, Corrosion Science, 86, p. 268-274. doi:https://doi.org/10.1016/j.co rsci.2014.06.004.

Dutra, J. C., Bonacorso, N. G., Gonçalves e Silva, R. H., Carvalho, R. S., Costenaro Silva, F. 2014. Development of a flexible robotic welding system for weld overlay cladding of thermoelectrical plants' boiler tube walls, Mechatronics, 24, 5, p. 416-425. Doi.10.1016/j.mechatronics.2014.03.002.

Elango, P. and Balaguru, S., 2015. Welding Parameters for Inconel 625 Overlay on Carbon Steel using GMAW, Indian Journal of Science \& Technology, 8, 31, p. 15.ISSN 0974.6846.

Elmer, J. W., Allen, S. M. and Eagar, T. W. 1989.Microstructural development During Solidification of Stainless Steel Alloys. Metallurgical Transaction A, 10A, p 2117-31.doi:10.1007/BF02650298.

Ghosh, P. K., Gupta, P.C. and Goyal, V. K. 1998.Stainless steel cladding of structural steel plate using pulsed current GMAW process. Welding Journal, 7, 7, p. 307-312.

Holmberg, B. and Bergquist, A. 2008. Suitable corrosion test methods for stainless steel welds, Welding in the World, 52, p 17-21.doi:10.1007/BF03266626.

Ibrahim, T., Yawas, D. S. and Aku, S. Y. 2013. Effects of gas metal arc welding techniques on the mechanical properties of duplex stainless steel. Journal of Minerals and Materials Characterization and Engineering. 1, p. 222-230. DOI:10.4236/jm mce.2013.15035.

Kang, Y. H. and Na, S. J., 2003, Characteristics of welding and arc signal in narrow groove gas metal arc welding using electromagnetic arc oscillation, The Welding Journal, AWS, p. 93-99.

Kannan, T. and Yoganandh, J. 2010. Effect of process parameters on clad bead geometry and its shape relationships of stainless steel claddings deposited by GMAW. International Journal for Advanced Manufacturing Technology, 47, p.1083-1095. doi:10.1007/s00170-009-2226-1.

Kanti, K.M., Rao, P.S. and Janardhana, G.R. 2013. Optimization of weld bead penetration in pulsed gas metal arc welding using genetic algorithm, International Journal of Emerging Technology and Advanced Engineering, 3, 3, ISSN 2250-2459, p. $368-371$.

Karlsson, L. 2000.Welding of stainless steels duplex and superduplex steel, Welding International, 14, p 5-10.Doi:http://dx.doi.org/10.1080/09507110009549131.

Khara, B., Mondal, N. D., Sarkar, A. and Das, S. 2011, on cladding performance of austenite stainless steel over low alloy steel plates using metal arc welding. In Proceedings of the National Welding Seminar, India,p. 51-62.

Khara, B., Mandal, N., D., Sarkar, A., Sarkar, M., Chakrabarty, B. and Das, S., 2016. Weld Cladding with Austenitic Stainless Steel for Imparting Corrosion Resistance, Indian Welding Journal, 49, 1, p. 75-81.

Kolahan, F. and Heidari, M., 2009.A new approach for predicting and optimizing weld bead geometry in GMAW, International Journal of Mechanical Systems Science and Engineering,2, 2, p. 138-142.

Kumar, S., Rao, P. S. and Ramakrishna, A. 2011. Effects of eccentricity and arc rotational speed on weld bead geometry in pulsed GMA welding of 5083 aluminum alloy. Journal of Mechanical Engineering Research, 3,6, ISSN: 2141-2383, p. 186-196.

Kumar, V., Singh, G. and Yusufzai, M. Z. K. 2012. Effects of process parameters of gas metal arc welding on dilution in cladding of stainless steel on mild steel, MIT International Journal of Mechanical Engineering, 2, 2, ISSN: 2230-7680, p. 127131.

Kwok, C. T., Cheng, F. T. and Man, H. C. 2000. Synergistic effect of cavitation erosion and corrosion of various engineering alloys in $3.5 \% \mathrm{NaCl}$ solution, Material Science 
Engineering Advanced, 290, p. 145-154. doi:https://doi.org/10.1016/S0921-5093 (00)00899-6

Lai, G. and Hulsizer, P.1999. Application of type 312 stainless steel overlay for corrosion protection of batch digesters, http://bit.ly/2BYOegn.

Lucas, W.1994. Arc surfacing and cladding processes to enhance performance in service and to repair worn components. Welding and Metal Fabrication, 62, 2, p. 55-60.

Mondal, A., Saha, M. K., Hazra, R. and Das, S., 2016. Influence of heat input on weld bead geometry using duplex stainless steel wire electrode on low alloy steel specimens, Journal of Cogent Engineering, 3, p. 1-14.doi: http://dx.doi.org/10.1080/ 23311916.2016 .1143598$.

Montgomery, C. D., 1984, Design and Analysis of Experiments, New York. John Wiley $\&$ Sons, Inc.

Munez, C. J., Utrilla, M. V., Ureńa, A. and Otaro, E. 2010. Influence of the filler material on pitting corrosion in welded duplex stainless steel 2205. Welding International, 24, p. $105-110$.

Murugan, N. and Parmar, R. S. 1997. Stainless steel cladding deposited by automatic gas metal arc welding, Welding Journal, 76, p. 391-403.

Nadkarni, S. V. 1988. Modern Arc Welding Technology, Oxford \& IBH Publishing Co. Pvt. Ltd.

Nouri, M., Abdollah-zadehy, A. and Malek, F. 2005. Effect of welding parameters on dilution and weld bead geometry in cladding, Journal of Material Science \& Technology, 23, 6, p. 817-822.

Prabhu, R., Alwarsamy, T., Ramkrishnan, R. and Gargyan, P. S., 2014, Development of mathematical model for prediction of convexity index in cladding by pulsed MIG welding process. In Proceedings on International Conference on Advances in Manufacturing and Materials Engineering, Procedia Material Science, 5, p. 663668.

Praveen, P., Kang, M. J. and Prasad, Y. K. D. V., 2006.Behaviour of metal transfer modes in pulse gas metal arc welding of aluminum. In Proceedings of Advanced Materials Processing Technologies Conference, Las Vegas, USA, p.1-8, 2006.

Purslow, M. A., 2013. Advanced Robotic GMAW Cladding Process Development, Abstract prepared for The Society of Naval Architects \& Marine Engineering, 2013, http://bit.ly/2E55Ehd.

Rao, N. V., Reddy, G. M. and Nagarjuna, S. 2011. Weld overlay cladding of high strength low alloy steel with austenite stainless steel - structure and properties, Materials and Design, 32, p. 2496-2506. https://doi.org/10.1016/j.matdes.2010.10.026.

Rao, P. S. 2004. Development of arc rotation mechanism and experimental studies on pulsed GMA welding with and without arc rotation, Ph.D. thesis, IIT Kharagpur, India.

Sabiruddin, K., Das, S. and Bhattacharya, A. 2009. Application of the analytic hierarchy process for optimization of process parameters in GMAW.Indian Welding Journal, 42, p. 38-46.

Sabiruddin, K., Bhattacharya, S. and Das, S. 2013.Selection of appropriate process parameters for gas metal arc welding of medium carbon steel specimens. International Journal for Analytical Hierarchy Process, 5, p.252-266.

Saha, M. K., Das, S., Bandyopadhyay, A. and Bandyopadhyay, S. 2012. Application of L6 orthogonal array for optimal selection of some process parameters in GMAW process. Indian Welding Journal, 45, 4, p. 41-45. doi:10.22486/iwj/2012 /v45/i4/141203. 
Saha, M. K. and Das, S. 2016. A review on different cladding techniques employed to resist corrosion, Journal of the Association of Engineers, India, 86, 1 and 2, ISSN 0368-1106, p.51-63.

Saha, M. K., Mondal, A., Hazra, R. and Das, S.2015.An overview on cladding through gas metal arc welding, proceedings of national welding seminar, Jamshedpur, India.

Sarkar, A. and Das, S. 2011.Application of grey-based Taguchi method for optimizing gas metal arc welding of stainless steel. Indian Welding Journal, 44, p.37-48.

Senthikumar, B., Birundha, P. and Kannan, T. 2014.Modelling and simulation of austenite stainless steel claddings deposition by gmaw. International Journal of Scientific \& Engineering Research, 5, ISSN 2229-5518, p. 363-370.

Senthilkumar, B. and Kannan, T., 2015. Effect of flux cored arc welding process parameters on bead geometry in super duplex stainless steel claddings, Measurement, 62, p. 127-136. Doi.10.1016/j.measurement.2014.11.007.

Serif, E. S. M., 2011. Corrosion behavior of duplex stainless steel alloy cathodically modified with minor ruthenium additions in concentrated sulfuric acid solutions. International Journal of Electrochemical Science, 6, p. 2284-2298.

Serif, E. S. M., 2012, Corrosion of Duplex Stainless Steel Alloy 2209 in Acidic and Neutral Chloride Solutions and its Passivation by Ruthenium as an Alloying Elements, International Journal of Electrochemical Science, 7, p. 2374-2388.

Shahi, A. S. and Pandey, S. 2008.Effect of auxiliary preheating of the filler wire on quality of gas metal arc stainless steel claddings. Journal of Materials Engineering and Performance, 17, p 30-36.doi:10.1007/s11665-007-9132-1.

Shahi, A. S. and Pandey, S. 2011. Weld bead geometry optimization of preheated fillerGMAW process for stainless steel surfacing using response surface methodology. Presented in Surface Modification Technologies XXV, Session-1 (Testing and Characterization), Sweden.

Shen, Z., Chen, Y., Haghshenas, M., Nguyen, T., Galloway, J. and Gerlich, A.P., 2015. Interfacial microstructure and properties of copper clad steel produced using friction stir welding versus gas metal arc welding, Materials Characterization, 104, p. 1-9. Doi.10.1016/j.matchar.2015.02.022.

Sreeraj, P. and Kannan, T. 2012.Modelling and prediction of stainless steel clad bead geometry deposited by GMAW using regression and artificial neural network models. Advances in Mechanical Engineering, 2012, p. 001-012. doi: 10.1155/20 $12 / 237379$.

Sreeraj, P., Kannan, T. and Maji, S. 2013a. Simulation and parameter optimization of gmaw process using neural networks and particle swarm optimization algorithm, International Journal of Mechanical Engineering \& Robotics Research, 2, ISSN 2278-0149, p. 130-146.

Sreeraj, P., Kannan, T. and Maji, S. 2013b. Sensitivity analysis of process parameters in cladding of stainless steel by GMAW, Journal of Machine Design, 5, 1, ISSN1821-1259, p. 001-010.

Sreeraj, P., Kannan, T. and Maji, S., 2013c.Optimization of weld bead geometry for stainless steel cladding deposited by GMAW, American Journal of Engineering Research, 02, 5, p.178-187.

Sugitiani, Y., Kobayashi, Y. and Murayama, M. 1991. Development and application of automatic high speed rotation arc welding, Welding International, 5, 7, p. 577-583.

Tasalloti, H., Kah, P. and Martikainen, J. 2014.Effects of welding wire and torch weaving on GMAW of S355MC and AISI 304L dissimilar welds. International Journal of Advance Manufacturing Technology, 6, 71, p. 197-205.doi:10.1007/s00170-0135484-x. 
Verma, A. K., Biswas, B. C., Roy, P., De, S., Soren, S. and Das, S. 2013a. Exploring quality of austenitic stainless steel clad layer obtained by metal active gas welding. Indian Science Cruiser, 27, 4, p. 24-29.

Verma, A. K., Biswas, B. C., Roy, P., De, S., Soren, S., and Das, S., 2013b. On the Performance of cladding Austenite stainlees steel on plain carbon steel. In Proceeding of the National Welding Seminar, Vishakhpattanum, India, 2013.

Verma, A. K., Biswas, B. C., Roy, P., De, S., Saren, S. and Das, S. 2014.On The Effectiveness of Duplex Stainless Steel Cladding Deposited by Gas Metal Arc Welding, e-Proceedings of the International Conference (IIWIC 2014), $67^{\text {th }}$ Annual Assembly of the International Institute of Welding, Seoul, Korea, 2014.

Verma, A. K., Biswas, B. C., Roy, P., De, S., Soren, S. and Das, S., 2017. An investigation on the anti-corrosion characteristics of stainless steel cladding, Indian Welding Journal, 50,3, p. 52-63.

Wang, Huei-Sen, 2005. Effect of welding variables on cooling rate and pitting corrosion resistance in super duplex stainless weldments, Materials Transactions, 46, p. 593-601.doi:http://doi.org/10.2320/matertrans.46.593.

Waszink, J. H. and Piena, M. J. 1986.Experimental investigation of drop detachment and drop velocity in GMAW. Welding Journal, 65, p. 289-298.

Wei, H. L., Li, H., Yang, L. J. and Gao, Y. 2013. Consumable double electrode with a single arc GMAW. The International Journal of Advanced Manufacturing Technology, 68, p. 1539-1550. doi:10.1007/s00170-013-4941-x.

WiseGEEK, 2016. WiseGEEK clear answers for common questions, "What is Cladding?" http://www.wisegeek.com/what-is-cladding.htm, dated 21.04.2016.

Zahrani, E. M. and Alfantazi, A. M., 2013. Hot corrosion of inconel 625 overlay weld cladding in smelting off-gas environment, Metellurgical and Materials Transactions A, 44A, p. 4671-4699.doi:10.1007/s11661-013-1803-y.

Zahrani, E. and Alfantazi, A., M., 2014. High temperature corrosion and electrochemical behavior of INCONEL 625 weld overlay in $\mathrm{PbSO}_{4}-\mathrm{Pb}_{3} \mathrm{O}_{4}-\mathrm{PbCl}_{2}-\mathrm{CdO}-\mathrm{ZnO}$ molten salt medium, Corrosion Science, 85, p. 70-86. Doi.10.1016/j.corsci.2014. 03.034 . 